\title{
El surgimiento de la megaurbanización Nordelta en la Región Metropolitana de Buenos Aires: consideraciones en torno a las nociones de ciudad-fragmento y comunidad purificada*
}

\author{
María Florencia Girola**
}

En este artículo se focaliza uno de los procesos más generalizados y polémicos que se registran en las grandes ciudades contemporáneas: el desarrollo de conjuntos residenciales que cuentan con seguridad y que sirven de vivienda permanente a los sectores medios y altos de la población. Más concretamente, intentamos cuestionar y examinar-desde una perspectiva etnográfica- las visiones sobre estos conjuntos ancladas en torno a la categoría de fragmentación urbana, a partir del análisis de un ejemplo especifico: la emergencia de grandes emprendimientos en la Región Área Metropolitana de Buenos Aires; en este caso se trata de una singular ciudad privada y periférica.

Palabras clave: urbanizaciones cerradas, Región Metropolitana de Buenos Aires, metodología cualitativa, fragmentación urbana, urbanismo escenográfico, urbanismo afinitario, motivos residenciales, comunidad, desolidarización.

Fecha de recepción: 3 de marzo de 2006.

Fecha de aceptación: 5 de julio de 2006.

* Los primeros datos de este artículo fueron elaborados en el marco del proyecto "Habiter quelle ville? Situations d'homogénéisation résidentielle et (re)définition de l'urbain et de l'urbanité dans les Amériques (2001-2003)" coordinado por Guénola Capron. Dicho proyecto fue beneficiado por una subvención del Plan Urbanisme Construction Architecture (PUCA), Ministère de L'Equipement, des Transports et du Logement, Programme de la Recherche Habitat et Vie Urbaine, cuya dirección en Buenos Aires estuvo a cargo de Mónica Lacarrieu. Actualmente la investigación continúa en el marco de una beca interna doctoral otorgada por el Conicet y de los siguientes programas: "Vivir en la ciudad: procesos contemporáneos de transformación urbana desde la perspectiva antropológica" (Conicet, 2004-2006), "Cultura y territorio" (Ubacyt, 20042007), ambos dirigidos por la doctora Mónica Lacarrieu. Agradezco a todos los miembros de estos equipos de investigación sus valiosos aportes. Finalmente, la mayor de las gratitudes hacia los habitantes de Nordelta que compartieron conmigo sus experiencias residenciales, en especial a Marcelo C. y a Héctor C. y su esposa.

** Becaria doctoral del Consejo Nacional de Investigaciones Científicas y Técnicas (Conicet); docente de la Facultad de Filosofía y Letras (UBA) y de la Facultad de Ciencias Sociales (UBA). Correo electrónico: fgirola@uolsinectis.com.ar. 
The Emergence of the Nordelta Megaurbanization in the Metropolitan Region of Buenos Aires: Considerations Regarding the Notions of Fragment City and Purified Community

This article focuses on one of the most generalized, polemic processes recorded in major contemporary cities: the development of residential complexes with security that serve as permanent housing for the middle and upper classes of the population. More specifically, the author attempts to use an ethnographic perspective to question the views on these complexes placed within the category of urban fragmentation on the basis of the analysis of a specific example; the emergence of major developments in the Metropolitan Area of Buenos Aires; in this case, an unusual private, peripheral city.

Key words: closed urbanizations, Metropolitan Region of Buenos Aires, qualitative methodology, urban fragmentation, scenographic town planning, similar town planning, residential motives, community, lack of solidarity.

\section{Introducción}

En las últimas décadas, en consonancia con el surgimiento de un nuevo régimen de acumulación de capital, las grandes ciudades del mundo han experimentado una serie de transformaciones simultáneas que han incluido, entre otras manifestaciones, un debilitamiento de sus centros tradicionales y la aparición de nuevas centralidades, una dispersión urbana inusitada (productiva, comercial, residencial, etc.), una creciente desintegración socioespacial y la reducción de las decisiones e inversiones públicas en materia de planificación y desarrollo metropolitano (Welch Guerra y Valentini, 2005: 10). Algunos autores situaron en 1973 -año de la crisis internacional del petróleo- el inicio de esta fase de expansión alternativamente conceptuada como ciudad global (Sassen, 1999), ciudad posmoderna (Amendola, 2000) o ciudad posfordista (Donzelot, 1999 y 2004), con el propósito de diferenciarla de la ciudad moderna industrial que creció durante buena parte del siglo Xx en función del eje centro y periferia.

Aunque estrechamente vinculadas a los impulsos uniformadores de la globalización, las reestructuraciones mencionadas presentan características específicas según los contextos regionales y nacionales que las contienen. Sin embargo, a pesar de los matices locales, la fragmentación (o nueva segregación) parece constituir una tendencia que se afianza en las ciudades contemporáneas. Este concepto, muy divul- 
gado en el debate académico de la Europa Occidental y la América anglosajona y latina, designa el pasaje de un modelo de ciudad compacta y orgánica a uno de ciudad dispersa y estallada, constituida por retazos urbanos sin ningún tipo de vínculo entre sí. De acuerdo con estas interesantes posturas, la conformación de áreas metropolitanas con base en "insularidades territoriales" socioculturalmente homogéneas hacia adentro es la principal característica de las urbes del siglo XXI, rasgo particularmente agudizado en los escenarios latinoamericanos (Prévôt Schapira, 1999 y 2001).

Indudablemente la difusión de conjuntos residenciales con seguridad aparece como la quintaesencia de la fragmentación, la máxima expresión del advenimiento de una ciudad archipiélago. Esta denominación engloba aquellos espacios que, controlados mediante diferentes dispositivos (alambres o muros perimetrales, alarmas, barreras, guardias armados), sirven de vivienda permanente a las capas medias y altas de la población. Estas modalidades residenciales - presentes en el paisaje de las grandes metrópolis con rótulos diferenciales de acuerdo al país (Thuillier, 2001) - son con frecuencia analizadas como "islas de riqueza y bienestar" producto del atrincheramiento de las élites y de su rechazo por los sectores populares que habitan en barrios relegados. ${ }^{1}$

En este artículo nos proponemos cuestionar y dilucidar estas percepciones sobre los conjuntos residenciales que con seguridad fueron construidos en torno a la categoría de fragmentación a partir del análisis de un caso específico: la emergencia de urbanizaciones privadas o cerradas en el Área Metropolitana de Buenos Aires. Seguiremos una línea de estudio que recupere paralelamente los desarrollos conceptuales sobre estos conjuntos y la focalización etnográfica en un caso particular y factible (Bourdieu y Wacquant, 1995: 173). Concentramos nuestra mirada en una de las formas más destacadas que ha asumido el fenómeno en el área seleccionada: los emprendimientos de gran magnitud, y más concretamente en la gestación de la urbanización Nordelta. Hemos seleccionado esta gran obra como universo de aná-

${ }^{1}$ El término "conjuntos residenciales con seguridad" constituye una categoría conceptual genérica que subsume la variedad del fenómeno. La noción hace referencia a un lugar de cohabitación y a sus espacios colectivos contiguos, vale decir, a un reagrupamiento residencial caracterizado por el cierre material de sus predios -tanto individuales como compartidos- y por la existencia de dispositivos de seguridad de diversa naturaleza. Las denominaciones locales son variadas: gated communities (comunidades fortificadas) en Estados Unidos, ensembles résidentiels sécurisés en Francia, alcabalas residenciales urbanas en Venezuela, fraccionamientos cerrados en México, condominios fechados en Brasil, y urbanizaciones cerradas o privadas en Chile y Argentina. 
lisis porque posee ciertos rasgos que la hacen un proyecto único, altamente representativo de las modalidades de intervención urbanística que hegemonizan las formas de "hacer ciudad" en la Argentina neoliberal, y por considerarla un ejemplo esclarecedor de las situaciones de segregación que se acentuaron en la aglomeración de Buenos Aires al compás de tales emprendimientos.

El artículo se nutre de un trabajo de campo antropológico que hemos venido desarrollando desde 2001 en diversas urbanizaciones cerradas de Buenos Aires, y desde 2004 en la megaurbanización Nordelta. La labor etnográfica nos ha permitido recobrar las construcciones de sentido de los actores comprometidos en la constitución del conjunto residencial que nos convoca, atendiendo a sus apropiaciones diferenciales y conflictivas del territorio. En tanto metodología cualitativa, la aproximación puesta en práctica -y aún en curso- se ha basado en nuestra presencia prolongada en el locus que constituye el referente empírico de la investigación y en las relaciones sociales establecidas con los interlocutores. De este modo, las estrategias de elaboración de datos incluyeron: observaciones de campo en las distintas áreas de Nordelta; realización de entrevistas (en profundidad y no directivas) a residentes, promotores inmobiliarios y funcionarios municipales; recolección de fuentes secundarias sobre el emprendimiento (folletos, videos y publicaciones).

Para llevar adelante nuestros objetivos hemos dividido la exposición en dos secciones. En un primer apartado contextualizamos brevemente el fenómeno de los conjuntos urbanos "con seguridad" de Buenos Aires para luego detenernos en una presentación pormenorizada del caso escogido. En un segundo momento recuperamos las prácticas y representaciones desplegadas por los residentes de Nordelta para confrontarlas con ciertos ejes constitutivos de los planteamientos teóricos anclados en la noción de fragmentación o nueva segregación urbana, a saber: las motivaciones que impulsan a los residentes a desplazarse hacia sus nuevas viviendas, la constitución de una forma específica de sociabilidad dentro de los emprendimientos -la comunidad purificada-, la gestión de la alteridad o la relación con los "otros externos" -especialmente con los sectores populares que rodean a las urbanizaciones. 


\section{La emergencia de urbanizaciones cerradas en el Área Metropolitana de Buenos Aires. Del proceso general al caso elegido: contextos, escenarios y actores}

En los últimos años el Área o Región Metropolitana de Buenos Aires (desde ahora AMBA o RMBA respectivamente) ha experimentado profundas transformaciones territoriales producidas en el contexto de una reconfiguración neoliberal que si bien ya se perfilaba en tiempos de la última dictadura militar (1976-1983), se acentuó años después. ${ }^{2}$ Más precisamente, fue durante la década menemista (1989-1999) que se consagró la hegemonía de un paradigma basado en la desindustrialización, el debilitamiento del Estado nacional, la privatización de los servicios públicos y la apertura financiera y comercial. Esta combinación de desregulación económica y reestructuración del Estado se tradujo en la acentuación de las desigualdades existentes y en la aparición de niveles inéditos de exclusión (Svampa, 2005: 10). ${ }^{3}$ Como era de esperarse, la RMBA no permaneció ajena a los efectos de estas tendencias.

Desde los años noventa se han venido desarrollando en el AMBA procesos de recalificación del espacio urbano que han incidido tanto en el remozamiento de la centralidad -generalmente asociada al centro histórico pero con extensión a otros lugares- como en el de la periferia; novedosas formas de construir, vivir y gestionar la ciudad que pusieron en juego la intervención de diversos actores sociales, primordialmente del mercado, el Estado y la sociedad civil (Lacarrieu, 2005: 368). ${ }^{4}$ Entre los cambios acaecidos en nuestra ciudad podemos men-

${ }^{2}$ La RMBA es un inmenso territorio (19 $680 \mathrm{~km}^{2}$ con 13700000 habitantes) que comprende las siguientes jurisdicciones: a) la Ciudad Autónoma de Buenos Aires -casco central de la región-, b) un anillo periférico integrado por 40 partidos o municipios que conforman el Gran Buenos Aires (GBA), también llamado conurbano bonaerense. Estos municipios son unidades político administrativas independientes de la Ciudad de Buenos Aires, ya que pertenecen a la Gobernación de la Provincia de Buenos Aires (Ciccolella, 1999). En virtud de esta diferenciación de jurisdicciones utilizaremos a lo largo del texto la noción de centralidad para referirnos a la Ciudad de Buenos Aires y el término periferia para aludir al Gran Buenos Aires.

${ }^{3}$ Estela Grassi ha realizado una extensa investigación sobre los procesos político culturales que han acontecido en el transcurso de los noventa, cuando se consolidó el Estado nacional asistencialista en Argentina. Como bien observa la autora, se trata de la transformación de signo negativo más profunda que ha atravesado el país (Grassi, 2003: 9).

${ }^{4}$ Los procesos de recualificación implican la iluminación selectiva de determinadas "porciones" de la ciudad que suponen ventajas diferenciales para el despliegue de negocios inmobiliarios en manos del sector privado o de alianzas mixtas. Esta modalidad de producción de las metrópolis, conocida como política de diseño del fragmento, se difundió en los noventa con base en la experiencia de Barcelona (Ríos, 2005b). 
cionar la recuperación con auspicio privado de áreas centrales antiguas y deterioradas -tales como la reconversión de Puerto Madero o el ennoblecimiento del Abasto-, la proliferación de centros comerciales e hipermercados, la construcción de hoteles internacionales y de edificios inteligentes como sedes empresariales, la ampliación de redes viales, y el surgimiento de nuevas opciones residenciales en el conurbano bonaerense. Esto último ha constituido, sin duda, el cambio más significativo ocurrido recientemente en el AMBA. ${ }^{5}$

Los emprendimientos que atraen a los sectores medios y mediosaltos hacia los suburbios reciben el nombre genérico de urbanizaciones cerradas o privadas. El término designa a los predios que incorporan como principal componente el cerramiento o la privatización de un área de uso exclusivo donde se concentran las viviendas y su entorno inmediato, y cuyo acceso se restringe a los propietarios por medio de mecanismos de vigilancia. El proceso de constitución de una urbanización cerrada comienza con la adquisición, a bajo costo, de tierras suburbanas próximas a los accesos viales privatizados. El uso productivo de estos terrenos, mayormente clasificados como rurales o semirrurales, es de baja rentabilidad, y escaso su valor en el mercado. Sin embargo a partir de la parcelación, el cerramiento y la oferta de servicios (infraestructura, recolección de residuos, seguridad las 24 horas, actividades recreativas y deportivas) se produce un proceso de valorización de la tierra que favorece su entrada en un mercado inmobiliario destinado a las clases medias y medias-altas (Ríos, 2005b).

Las urbanizaciones bonaerenses abarcan una gran variedad de modalidades y tamaños: desde los minibarrios, con su única calle central bordeada de casas, hasta los megaemprendimientos, de 500 hectáreas en adelante; de los barrios cerrados (protagonistas indiscutidos del "boom" de los noventa) a los countries (viejos clubes de campo que mutaron de vivienda de fin de semana a residencia permanente); de los clubes de chacras (con terrenos individuales de 3 ha promedio) a las estancias

\footnotetext{
${ }^{5}$ Durante los noventa se difundieron en la Ciudad de Buenos Aires las llamadas "torres-jardín" (emprendimientos verticales con confort y equipamiento), versiones porteñas y con la altura de las urbanizaciones bonaerenses. Sin embargo este proceso no tuvo una "espectacularidad" -en términos de velocidad y repercusión mediática- semejante a la instauración de conjuntos con seguridad en el Gran Buenos Aires (Welch Guerra y Valentini, 2005: 74). Asimismo los noventa tuvieron una faceta mucho menos rutilante que la mencionada: en simultaneidad con los procesos de remozamiento, el AMBA asistió al aumento de la población residente en villas de emergencia, a la formación de nuevos asentamientos precarios, a la disminución de inversiones públicas en materia de planes habitacionales, al debilitamiento de estrategias tendentes a construir una ciudad con sentido social.
} 
privadas que remiten a lo ecuestre y a la puesta en escena de la memoria y la tradición. ${ }^{6}$ Todos los emprendimientos se han situado a una distancia promedio de 30 a $70 \mathrm{~km}$ de la ciudad centro. En este sentido, el traslado de las capas más favorecidas hacia el suburbio lejano, ampliamente habitado por los sectores populares, marcó una ruptura respecto de las modalidades previas de periurbanización del Gran Buenos Aires (desde ahora GBA). ${ }^{7}$

Para finalizar esta presentación general cabe mencionar que según datos de la Federación Argentina de Clubes de Campo -entidad que reúne muchos emprendimientos-, las urbanizaciones cerradas cuadruplicaron su número en los últimos 15 años: de 140 urbanizaciones en 1990 se pasó a 600 en 2004, el número de casas construidas se elevó de 11000 a 50 000, las familias residentes en forma permanente aumentaron de de 1000 a 35 000. En el eje norte del AMBA (históricamente su zona más acomodada) se ubicó $67 \%$ de los emprendimientos, $16 \%$ en el oeste, y $8 \%$ en el sur (área tradicionalmente relegada), mientras el $9 \%$ restante lo hizo en el interior del país -principalmente en Córdoba y Rosario. ${ }^{8}$

\section{El nacimiento de Nordelta: la ciudad fuera de la ciudad}

Como hemos indicado, los megaemprendimientos cerrados constituyen una de las tipologías existentes en el mercado bonaerense. Estas obras

\footnotetext{
${ }^{6}$ Varios autores han elaborado tipologías detalladas que clasifican las urbanizaciones cerradas del mercado (Lacarrieu, 1999; Svampa, 2001); sus reseñas exceden este espacio.

${ }^{7}$ Entre 1940 y 1970, dentro de un proceso de industrialización basado en la sustitución de importaciones y en políticas estatales tendentes a la redistribución de los ingresos, se produjo una reactivación del crecimiento metropolitano. En esta coyuntura los trabajadores urbanos accedieron a la propiedad de la vivienda mediante "loteos económicos" periféricos. Para ello fueron de vital importancia los fuertes subsidios estatales que abarataron los costos del transporte público y facilitaron así los desplazamientos de la residencia al trabajo. Se trató de un proceso muy diferente respecto del ocurrido en los noventa.

${ }^{8}$ Entre los analistas económicos hay acuerdo en que desde fines de 2003 se ha producido un relanzamiento del mercado inmobiliario, principalmente debido al consumo de los sectores medios-altos y altos (profesionales independientes, gerentes, empresarios, microemprendedores, comerciantes). Luego de la crisis socioeconómica y de la devaluación del periodo 2001 a 2002, estos grupos - $10 \%$ de la población que concentra $40 \%$ de los ingresos- parecen haber sido los únicos capaces de adquirir viviendas (con fines residenciales o como inversión) en un contexto de alza de precios y escasez de créditos. Fuentes: diario Página 12, Suplemento Económico, 18/08/04; diario Clarín, Suplemento Countries, 24/12/04; diario La Nación, Suplemento Countries, 27/08/05.
} 
se distinguen por sus grandes dimensiones, porque ofrecen una integralidad de servicios (educativos, comerciales, médicos, deportivos, etc.) con que se aspira a convertirlas en ciudades autosuficientes, porque poseen un plan maestro -masterplan- que regula todas las etapas de su desarrollo. Según los medios de comunicación y los promotores inmobiliarios, los "mega" -cuyos inicios se remontan a fines de los noventa- conforman la nueva tendencia en el campo de las urbanizaciones privadas; asimismo representan el ocaso de los inversores particulares en favor de los grandes capitales financieros y de los bienes raíces de carácter internacional en el mercado residencial (Ríos, 2005b: 8). Los emprendimientos de estas características que tiene el GBA reúnen a un total de 2000 familias, la mitad de las cuales vive en Nordelta -cifra que lo convierte en el gran conjunto más poblado hasta la fecha. ${ }^{9}$

El origen de Nordelta se remonta a los años setenta, cuando dos empresas nacionales con experiencia en los rubros de saneamiento, infraestructura y construcción de vivienda social -DYOPSA (Dragados y Obras Portuarias Sociedad Anónima) y Supercemento SAIC- adquirieron a bajo precio 1600 ha del partido de Tigre, un municipio situado en el eje norte del Gran Buenos Aires. ${ }^{10}$ Inmediatamente después de su adquisición, los flamantes propietarios de las tierras comenzaron a soñar con la constitución de un "emprendimiento urbano integral" al estilo de las master planned comunities estadunidenses y de las villes nouvelles ubicadas en las afueras de París. ${ }^{11}$ Con la conformación de un equipo interdisciplinario encargado de elaborar el plan director de la nueva centralidad tigrense se sentaron las bases para la reconversión

${ }^{9}$ Fuente: diario Clarín, 25/09/05. Los datos cuantitativos citados ponen de relieve que las urbanizaciones cerradas están lejos de conformar la modalidad habitacional más difundida del GBA. No obstante las consecuencias socioculturales del fenómeno trascienden las mediciones numéricas.

${ }^{10}$ Tigre se localiza a $30 \mathrm{~km}$ aproximadamente de la Ciudad de Buenos Aires y como todos los municipios del conurbano bonaerense presenta altos porcentajes de población con necesidades básicas insatisfechas (27\% de una cantidad total estimada en 301223 habitantes según datos del Instituto Nacional de Estadísticas y Censos) y deficiente cobertura de servicios urbanos tales como red de agua corriente y cloacas (Ríos, 2005b). La localidad posee una geografía singular que fundamenta su larga tradición en viviendas de fin de semana: nos referimos al extenso sector isleño conformado por el delta de los ríos Luján, Reconquista y Paraná. Tanto los islotes y riachos como la flora y la fauna del delta de Tigre son altamente valorados por los residentes del AMBA.

${ }^{11}$ Muchas grandes ciudades cuentan con emprendimientos de este calibre: a modo de ejemplo podemos nombrar el complejo urbanístico de Alphaville en San Pablo, y el caso de Cergy-Pontoise en las afueras de París, cuyos responsables asesoraron a los responsables de Nordelta. 
de un espacio que contaba con inigualables valores estratégicos: su proximidad a la ciudad central y sus cualidades paisajísticas (con los canales de agua como elemento distintivo). Desde la perspectiva de los hacedores de Nordelta, su plan maestro sería el "antídoto" para combatir los "males" urbanos (caos, contaminación, crecimiento desordenado e inseguridad), una herramienta insustituible para crear una ciudad nueva que fuera la contracara de las patologías condensadas en la centralidad histórica de Buenos Aires.

La aprobación del masterplan por parte del Gobierno de la Provincia de Buenos Aires llegó en 1992, pero las obras comenzaron en 1998 a partir de la incorporación del empresario Eduardo Constantini en el directorio de Nordelta S. A.; fue él quien le imprimió al proyecto su perfil actual. ${ }^{12}$ Las grandes inversiones realizadas por Consultatio S. A. (muchas de ellas provenientes de capitales suizos) favorecieron el acondicionamiento de las pantanosas tierras de Tigre; se destinaron fundamentalmente a la excavación de enormes superficies, a su elevación mediante terraplenes y a la creación de un sistema lacustre artificial para el disfrute de los futuros residentes. ${ }^{13}$

Congruencia y previsibilidad son dos categorías recurrentes en boca de los responsables del plan director y de los equipos de venta del emprendimiento, ampliamente apropiadas por quienes eligieron vivir en Nordelta. Ambas aluden a su cuidadosa planificación y a la integración de sus áreas residenciales, comerciales, educativas y deportivas, a la solidez económica de los desarrolladores y a la seguridad jurídica que ofrece la compra de lotes con escritura inmediata. ${ }^{14}$

Nordelta cuenta hoy con nueve barrios cerrados conectados por una avenida central (Avenida de Los Lagos, de Los Fundadores o

${ }^{12}$ Eduardo Constantini es la cara visible de Consultatio S. A., una empresa dedicada a la administración de fondos de inversión y al desarrollo de emprendimientos inmobiliarios (tanto en la periferia bonaerense como en la ciudad centro). Nos referiremos más adelante a este empresario y a la importancia de su figura entre los residentes de Nordelta.

${ }^{13}$ Todas las urbanizaciones cerradas de Tigre requirieron de un proceso de polderización, es decir, de la construcción de terraplenes o diques perimetrales que se rellenaron con tierra o lodo para protegerlas de eventuales inundaciones. Este sistema constructivo que mitigó los riesgos de unos, aumentó la vulnerabilidad y el riesgo de otros: de los asentamientos precarios y populares que se sitúan en los espacios intersticiales que dejan las urbanizaciones cerradas (Ríos, 2005a).

${ }^{14}$ Con relación a este punto cabe mencionar que la "confianza" que inspira en los propietarios el respaldo que Consultatio S. A. brinda a Nordelta suele contraponerse con la "desconfianza" que les generan las empresas Pentamar-Eidico (Emprendimientos Inmobiliarios de Interés Común), responsables de emprendimientos tigrenses vecinos que enfrentan serios problemas de escrituración. 
simplemente denominada "La Troncal" por los vecinos) y con un extenso camino de circunvalación; sus calles laberínticas rompen con el trazado amanzanado que ha guiado por décadas la expansión del AMBA. La referencia a la naturaleza y al deporte es una constante en el nombre de sus barrios (Los Castores, La Isla, Las Caletas, Las Glorietas, La Alameda, Barrancas del Lago, Los Sauces, Portezuelo, Nordelta Golf Club), lo cual muestra la importancia que se les concede como elementos configuradores del interior. Cada uno de éstos se presenta como un producto dirigido a determinado segmento del mercado: Las Glorietas y La Alameda, por ejemplo, apuntan a familias jóvenes que acceden a su primera vivienda; Las Caletas está orientado a compradores con alto poder adquisitivo que practican actividades náuticas; Barrancas del Lago ofrece terrenos y casas prefabricadas por la empresa estadunidense Pulte; Portezuelo se caracteriza por sus dúplex para parejas jóvenes o de la tercera edad; La Isla es el barrio más exclusivo del complejo.

La infraestructura urbana también incluye tres colegios privados bilingües de niveles inicial, primario y secundario (aún no posee establecimientos universitarios), un club deportivo, un centro médico y un centro comercial de reciente creación. ${ }^{15}$ Desde que la primera familia se instaló en 1999 la megaurbanización ha crecido considerablemente y cuenta ya con 5000 habitantes, pero sus artífices proyectan un total de 20 barrios con una población estimada en 80000 personas o más.

Para destacar que esta ciudad es ecológica y sustentable, como suelen hacer los desarrolladores, se acuñó un término que recurre a nociones difundidas y socialmente valoradas: "Nordelta es la primera ciudadpueblo de la Argentina. Un espacio ideal para disfrutar del río, el verde, el aire puro. Con todas las facilidades de una ciudad: vivienda, educación (colegios), salud, centro de oficinas, centro comercial, de-

\footnotetext{
${ }^{15}$ Las intenciones del centro comercial han sido coherentes con el "espíritu" del emprendimiento: reinventar las calles comerciales de los viejos pueblos, en franca oposición a los shopping center que florecieron en los noventa. Para ello se ha recurrido a un estilo urbanístico arquitectónico que privilegia las zonas peatonales al aire libre. Sin embargo, los elegantes negocios que lo integran se asemejan más a los shopping porteños que a un "paseo de pueblo": casas de computación y alquiler de DVD, solarium y spa, casas de decoración, indumentaria y calzado, farmacia, banco, inmobiliarias; todos de reconocidas marcas. En este sentido, algunos residentes se han quejado porque el centro comercial carece de rubros que se necesitan cotidianamente, tales como mercería o ferretería. Además, hasta fines de 2005 la ciudadpueblo no contaba con un supermercado donde realizar las compras diarias, de ahí que los residentes se vieran en la necesidad de frecuentar localidades del GBA "profundo".
} 
portes, recreación, y con la tranquilidad y seguridad de un pueblo", rezan sus folletos publicitarios en un intento por aclarar esa inédita conjunción de términos. Desde la perspectiva de sus artífices, la creación de este lugar utópico ${ }^{16}$ que combinaría infraestructura urbana con sociabilidad pueblerina, ameritaba el neologismo: un término nuevo para "bautizar" un espacio único y novedoso, a la vez "integral y accesible, diverso y planificado". ${ }^{17}$

La génesis de la ciudadpueblo significó la "conquista" de terrenos en desuso del GBA, su puesta en valor por medio de la estetización del miedo (Zukin, 1996) y de la domesticación de la naturaleza. Esta presencia de la naturaleza no remite necesariamente a la genuina preocupación ambiental de los residentes, sino a un recurso escénico en manos de los desarrolladores de Nordelta, a una naturaleza devenida en apariencia, artificio que tiende a ocultar y estetizar la característica más polémica de éste y otros tantos emprendimientos semejantes, es decir, la producción de seguridad por medio de agencias privadas. Estas intervenciones del urbanismo escenográfico -cada vez más frecuentes en parques temáticos, barrios gentrificados, etc.- apuntan a la consolidación de una ciudad de lugares únicos y "pintorescos" donde el derecho a la belleza y el placer adquieren gran relevancia (Amendola, 2000). ${ }^{18}$

Mediante el proceso de recualificación que supuso un emprendimiento como Nordelta, los espacios vacantes del GBA resultaron subsumidos en un paisaje privatizado cuya finalidad consistió en otorgarle un nuevo sentido al lugar (Zukin, 1996): 19 "Nordelta Ciudadpueblo

${ }^{16}$ En un trabajo anterior hemos reflexionado sobre las prácticas y representaciones sociales de los habitantes de las urbanizaciones bonaerenses a partir de las nociones de lugar utópico o proyectado, lugar tópico o vivido, lugar heterotópico o temido. La primera de ellas nos ha llevado a analizar los emprendimientos como productos urbano residenciales diseñados por los desarrolladores, promocionados por el sector inmobiliario y soñados por los residentes (Girola y Lacarrieu, 2004).

${ }^{17}$ Las urbanizaciones cerradas en general, y Nordelta en particular, retoman ciertos elementos estructurantes de la modernidad urbana, aunque actualizados conforme al nuevo contexto: organización y racionalización de un territorio cerrado y privatizado, especialización de sus múltiples áreas, distinción de accesos (para propietarios, visitas y proveedores), sedes sociales y deportivas que funcionan como lugares de encuentro, integración de la totalidad urbana mediante vías de circulación. En este sentido, los conceptos de nuevos espacios de la modernidad (Lacarrieu, 1999) o de espacios de la modernidad reciente (Zukin, 1996) son muy apropiados para referirse al fenómeno en cuestión.

${ }^{18}$ Se trata de un nuevo urbanismo que ha venido a reemplazar-aunque no en forma total- la rigidez y monotonía del planeamiento urbano funcional modernista, destacando el diseño como principio estructurador de las ciudades (Amendola, 2000: 31).

${ }^{19}$ Tomamos la noción de paisaje urbano de S. Zukin (1996), quien con el paisaje designa al ordenamiento espacial impuesto o al ambiente socialmente construido que combina el poder político y económico con la legitimación cultural. 
tiene como principal objetivo crear un cambio real en la calidad de vida de sus habitantes a través de un desarrollo urbano integral" (folleto de presentación). En este sentido, el video que promociona la ciudadpueblo resulta sumamente ilustrativo de esta colonización de espacios vírgenes, del nacimiento de lo nuevo a partir de lo vací:20 "el espíritu de los pioneros y el coraje de los colonizadores logró fundar una comunidad allí donde antes crecían pastos duros".

El nacimiento de Nordelta siempre suelen referirlo sus desarrolladores en forma grandilocuente y es rememorado como gesta heroica por su empresario estrella, Eduardo Constantini. Esta "épica" la fortalece, por ejemplo, la revista Nordelta con su permanente tendencia a citar cifras astronómicas (cantidad de dinero invertido por Nordelta $\mathrm{S}$. A., número de casas construidas por año, cantidad de familias que se mudan por día, etc.). La estrategia no es inocente: destacando el carácter faraónico de la obra se pretenden generar entre los compradores de lotes sentimientos de confianza, protección y "lealtad" hacia la empresa. ${ }^{21}$

\section{Iniciativas privadas y laissez faire estatal}

La instalación de los conjuntos residenciales con seguridad nunca habría sido posible sin la anuencia -inicialmente tácita y luego explícita- de los organismos públicos pertinentes que favorecieron el pro-

${ }^{20}$ En otro escrito (Girola, 2005b) hemos recurrido a esta metáfora para confrontar las urbanizaciones periféricas con los procesos de recualificación que se ejecutan en áreas centrales (Puerto Madero o Abasto), donde lo "nuevo" nace de lo "viejo" (remodelación de los silos portuarios y del antiguo Mercado Central, respectivamente).

${ }^{21}$ Dos publicaciones internas y claramente diferenciadas circulan entre los residentes. Por un lado la revista bimestral producida por Nordelta S. A., de distribución gratuita y a cargo de una integrante de la familia Constantini, cuyo contenido incluye diferentes secciones: ecología, paisajismo, deportes, arquitectura, agenda cultural, y una infaltable entrevista con algún residente famoso, ya sea deportista, actor, periodista o modelo. Por su tono laudatorio, este producto ha sido una valiosa herramienta para reconstruir los relatos oficiales sobre el emprendimiento. Por otro lado, la ciudadpueblo cuenta con un proyecto comunicativo "independiente que busca hacer periodismo de forma libre e imparcial", surgido por iniciativa de un particular. La evolución de su formato en tan sólo dos años -de newsletter distribuido por email a la versión impresa- da cuenta de su gran difusión entre los vecinos. Este periódico no solamente se permite cuestionar ciertas maniobras de Nordelta S. A., sino que incorpora temas que no aparecen en la publicación precedente, y que seguramente son menos glamorosos pero más próximos a las preocupaciones de los residentes entrevistados: costo de las expensas, injerencia del municipio, formas internas de gobierno de cada barrio, cartas de vecinos, etcétera. 
ceso tentados por las ganancias que resultarían del traslado de los nuevos vecinos (Girola, 2005: 11). Un funcionario municipal de Tigre, puntualizando la política territorial del partido y las acciones técnicas que habían realizado los desarrolladores nos comentaba:

Vos pensá que Tigre era un partido con el $50 \%$ de la tierra bajo cota, o sea que era tierra inundable [...] Las urbanizaciones contribuyeron a la reversión de esa situación porque son ante todo grandes obras hidráulicas, de refulado. Las urbanizaciones cerradas son el medio, no el fin, es el medio que encontró este partido para desarrollarse.

Tanto las intendencias como la Gobernación de la Provincia de Buenos Aires han buscado equilibrar sus deficitarias cuentas valiéndose de los impuestos que pesan sobre los residentes de los emprendimientos (permisos de construcción, rentas, alumbrado, barrido y limpieza), incluso a costa de la cesión de tierras públicas y aun cuando no quede claro si los beneficios se tradujeron en un mayor bienestar de la empobrecida población preexistente. Así, el interés por seducir a futuros moradores parece haber estimulado una singular competencia local: mientras cada partido busca explotar sus encantos para atraer nuevos vecinos contribuyentes, los emprendimientos cerrados compiten entre sí por la atracción de potenciales clientes compradores, redoblando sus apuestas en pos de ofertas cada vez más integrales y exclusivas. ${ }^{22}$

Como vemos, se hace necesario cuestionar la divulgada noción sobre el retiro del Estado en favor de una mirada que nos permita comprender las articulaciones entre los actores públicos y los privados que se construyen en contextos específicos. Otras investigaciones apuntan en una dirección similar, remarcando la participación del Estado en sus diferentes jerarquías, su rol como acondicionador y promotor de las inversiones privadas -nacionales o extranjeras- que se produjeron en el Gran Buenos Aires en materia urbano residencial. Estas afirmaciones son más que apropiadas en el caso de Tigre, ya que allí se ha puesto en práctica una política de marketing urbano orientada a facilitar las inversiones privadas (Ríos, 2005a y 2005b). ${ }^{23}$

${ }^{22}$ Esta competencia es particularmente visible en las publicidades que aparecen en los suplementos especializados de los principales diarios del país (Clarín y La Nación). Allí cada municipio destaca sus rasgos únicos y cada urbanización elitiza sus ofertas: barrios cerrados a los que sólo se accede navegando; casas que incluyen parrilla, quincho y frigobar en la habitación principal; conexión a través de sistemas de internet de alta velocidad de todos los residentes y sectores que integran la urbanización.

${ }^{23}$ Algunas de las obras emprendidas con la coparticipación del municipio -políti- 
En este sentido, las relaciones de las autoridades del partido con Nordelta han sido fluidas: se le ha declarado de interés municipal y provincial, y el Estado local no ha dudado en otorgar fondos públicos para apoyar el emprendimiento, aunque sea indirectamente. Así debe entenderse la repavimentación de una ruta provincial lindera y la prolongación del Acceso Bancalari-Benavidez (financiado junto con la municipalidad de San Fernando y otras urbanizaciones del corredor). Esta última medida ha sido de vital importancia para cimentar lo que los medios de comunicación han denominado "el Nuevo Tigre". ${ }^{24}$

Sin embargo el presente de la ciudadpueblo dista del proyecto que soñaron los propietarios originales y que fuera ratificado por la intendencia de Tigre. Si bien el plan director alude a una cuidad abierta compuesta por barrios privados unidos por calles públicas, hasta la fecha todos sus accesos permanecen cerrados, imponiendo a quien ingresa, sea visita o proveedor, una doble vigilancia (los propietarios poseen tarjetas magnéticas para entrar al emprendimiento y al barrio donde residen, pero se les revisa cuando visitan otro espacio residencial); "barrios cerrados dentro de una ciudad cerrada", según comentan los vecinos de fuera. ${ }^{25}$ Asimismo, la interminable demora en la construcción de la estación de tren -que ha pesado como motivo residencial entre algunos de sus habitantes- ha provocado la inserción incompleta de Nordelta en la trama vial y ferroviaria de este rincón del conurbano bonaerense.

Para finalizar este apartado hemos de llamar la atención sobre dos situaciones que estimamos reveladoras de las complejas relaciones

camente manipuladas como postales del éxito (Ríos, 2005b)- incluyeron: la parquización de su costanera, el mejoramiento del Puerto de Frutos, la construcción de plazas, la instalación de complejos recreativos (Parque de la Costa y Casino), entre otros procesos. En un indicio inequívoco del compromiso del poder público con ciertos desarrollos privados, el primer número en papel del Periódico de los Vecinos de Nordelta se abrió con una entrevista al intendente tigrense donde se abordaron cuestiones de suma importancia para el emprendimiento.

${ }^{24}$ En este corredor se han dispuesto, además de Nordelta, otras cuatro urbanizaciones cerradas, un colegio bilingüe y un centro comercial en fase de edificación.

${ }^{25}$ En el emprendimiento operan siete empresas privadas de seguridad que se han dividido la prestación del servicio en los siguientes sectores: el perímetro, las nueve áreas residenciales, el centro comercial, el supermercado, el centro médico y los colegios. Desde 2005 se han sumado guardaespaldas que acompañan a ciertos vecinos. Cabe destacar aquí que cualquier visitante no propietario debe pasar por dos puestos de control: en la entrada del conjunto y en cada barrio, donde el procedimiento puede ser más puntilloso, ya que a la exhibición de documentos personales y a la autorización del propietario se puede sumar la requisa del vehículo. Por último es preciso mencionar que también se controlan los egresos. 
entre las instancias públicas y las privadas que operan en la gestión urbana de este tipo de territorios.

El primero de estos episodios se suscitó en 2004, cuando los propietarios del Centro Comercial Nordelta reclamaron la apertura de la Avenida de los Lagos hacia las rutas municipales a fin de aumentar sus alicaídas ventas (junto a este centro se ubican un local de Mac Donald's y una estación de servicio Petrobrás). La demanda era jurídicamente aceptable puesto que el plan aprobado por el municipio reconoce su carácter público y sólo admite un cierre transitorio en tanto se concluyan las obras. El pedido de los comerciantes generó una intensa discusión que ha sido rememorada por todos nuestros entrevistados: los vecinos se movilizaron, juntaron firmas y se reunieron personalmente con Eduardo Constantini para exigirle que La Troncal permaneciera cerrada, argumentando que de lo contrario se verían afectadas la seguridad y la conservación de los senderos verdes que jalonan su recorrido, y que tampoco estaban dispuestos a dejar que otros usufructuaran algo que no pagan. La solución llegó de la mano de un camino público alternativo -de tierra, más largo, en regular estado y poco transitado por vehículos particulares pero sí por camiones de obra-que conduce al paseo comercial. Como para que no quedaran dudas respecto de la supremacía de los intereses privados por sobre las ordenanzas municipales -pese a ser leyes superiores al decreto de creación de cualquier urbanización-, un vendedor inmobiliario de la ciudadpueblo nos comentaba: "cuando todo esté completamente vendido Nordelta debería abrir al público el camino, tal fue el acuerdo con el municipio, pero Eduardo piensa liberar la obra el día del arquero" (registro de campo, abril de 2004). ${ }^{26}$

La segunda situación remite a una discusión vigente, producto de una serie de propuestas de la municipalidad de Tigre: la instalación -en La Troncal- de policías de tránsito habilitados para cobrar multas

${ }^{26}$ En los últimos tiempos se ha reavivado la polémica en torno al estatus de La Troncal. Algunos residentes han expresado su voluntad de otorgar credenciales para que los vecinos de urbanizaciones cerradas próximas (especialmente los que mandan a sus hijos a los colegios de Nordelta) accedan a la misma mediante el pago de un arancel, con la consiguiente disminución de los gastos que se facturan en las expensas de los "nordelteños" por el mantenimiento de esta avenida. Nuevamente, una rotunda mayoría rechazó esta opción con una contundente argumentación: "si quieren disfrutar de los beneficios de la ciudadpueblo que compren un lote y paguen por ello como cualquier propietario" (Periódico de los Vecinos de Nordelta, carta de Lectores correspondiente a la edición del 02/02/06). La discusión es ilustrativa de una concepción patrimonialista de la ciudadanía, del predominio otorgado a la propiedad privada como eje constitutivo del acceso a bienes y servicios urbanos (Svampa, 2005: 80). 
por exceso de velocidad $;{ }^{27}$ la inauguración de una delegación municipal dentro del emprendimiento (donde se podría obtener el registro de conductor, celebrar casamientos, realizar cambios de domicilio y así habilitar a los nuevos vecinos a votar en Tigre); la recolección de basura y el barrido de sus calles. ${ }^{28}$ Estos ofrecimientos forman parte de una estrategia del intendente, empeñado abiertamente en lograr una mayor integración de la ciudadpueblo al partido y en sumar votantes para futuros comicios, aunque de modo mucho más solapado. ${ }^{29}$

Con el debate planteado, los vecinos sopesan las ventajas y desventajas de las medidas propuestas y revelan una permanente tensión entre las aspiraciones de reducir costos económicos y la voluntad de mantener ciertas características del emprendimiento altamente valoradas. En este sentido, si el servicio de barrido municipal resulta tentador porque reduciría expensas, el que lo ejecuten beneficiarios de planes sociales con frecuente rotación podría repercutir negativamente en la seguridad. Asimismo, con la recolección de residuos a cargo del municipio las huelgas de camioneros disminuirían la higiene de Nordelta.

Más allá de la innegable presencia de límites perimetrales que se imponen con toda la fuerza de su materialidad, estimamos que las situaciones reseñadas ponen de manifiesto la porosidad de todas las fronteras sociales que distinguen "adentros" de "afueras" y "nosotros" de "otros", injerencia pública de competencias privadas. Como observa Ángela Giglia (2001), incluso en el caso de los conjuntos residenciales con seguridad, los límites son siempre construcciones dinámicas que -sujetas a conflictos y disputas- tienden a fortalecerse o debilitarse según las cambiantes coyunturas sociales. ${ }^{30}$

${ }^{27}$ Hasta ahora, los Tribunales de Disciplina de cada barrio se encargan de fijar sanciones económicas, que siempre recaen sobre los propietarios aun cuando las infracciones sean cometidas por sus allegados, y que se destinan a gastos internos. Cuando las trasgresiones se cometen en los espacios compartidos de la ciudadpueblo, las multas son impuestas por la denominada Asociación Vecinal Nordelta (AVN).

${ }^{28}$ Con las expensas los propietarios pagan por la limpieza de sus barrios (a cargo de las respectivas administraciones) y de los espacios comunes (en manos de la AVN). Además, abonan una tasa municipal por alumbrado, barrido y limpieza, aunque no reciban servicio alguno.

${ }^{29}$ Ricardo Ubieto desempeña su cuarto mandato como intendente por el partido vecinalista Acción Comunal de Tigre. Una amplia mayoría de los residentes entrevistados en Nordelta y en urbanizaciones privadas aledañas se ha mostrado conforme con las sucesivas gestiones de este funcionario.

${ }^{30}$ Esta autora ha enfatizado el carácter dinámico de la autosegregación de los sectores medios y altos en conjuntos residenciales privados: no se trata de un estado de cosas definitivo ni supone fronteras infranqueables; es un proceso social dinámico, inserto en relaciones sociales y por tal motivo sujeto a negociaciones (Giglia, 2001: 11). 


\section{Experiencias del habitar en Nordelta: ¿̇el advenimiento de una ciudad fragmentada?}

Expusimos en la introducción que una serie de interesantes enfoques han adoptado el concepto de fragmentación o nueva segregación para caracterizar las tendencias sobresalientes que modelan actualmente a las metrópolis del mundo, y entre ellas se cuenta la instauración de conjuntos con seguridad como el que hemos descrito. Según los sugerentes trabajos de Donzelot (1999 y 2004), la desindustrialización y la globalización que sacuden a los países centrales y periféricos desde los años ochenta vienen cimentando ciudades fracturadas donde concurren tres procesos paralelos: la relegación de los sectores populares en las viviendas sociales; la gentrificación de los centros históricos habitados por las clases altas; la periurbanización de las capas medias en residencias vigiladas.

De acuerdo con estas perspectivas, la instalación de emprendimientos cerrados es producto de la búsqueda de seguridad por parte de ciertos sectores que pretenden romper relaciones con el "afuera", huyendo del contacto con las zonas empobrecidas. Se trata de casos extremos de un "urbanismo afinitario enervado" que surge del miedo a la inseguridad y a las revueltas protagonizadas por los excluidos (las "incivilités" o incivilidades). Movidos por este sentimiento, los periurbanos se refugian en el entre nos protector y homogéneo que proveen sus modalidades privadas del habitar, fuertemente asociadas a ideales comunitarios (Jaillet, 1999 y 2004). Estos procesos entrañan indiferencia respecto de las condiciones de vida en los barrios relegados; una desolidarización (Donzelot, 1999 y 2004) que puede manifestarse de varias maneras: desde la desvinculación impositiva hasta exigencias de secesión que podrían convertir a los conjuntos con seguridad en enclaves política y jurídicamente autónomos. ${ }^{31}$

Muchos autores que han seguido estas líneas de investigación vienen advirtiendo sobre el progreso de las tendencias a la fragmentación en las urbes latinoamericanas en general y en la aglomeración de Buenos Aires en particular (Prévôt Schapira, 1999 y 2001). Aquí el antiguo modelo de ciudad orgánica (compacta e integrada) estaría

${ }^{31}$ Las nociones de periurbanización, urbanismo afinitario y desolidarización han sido utilizadas por Donzelot (1999 y 2004) y Jaillet (2004) para documentar el traslado de las clases medias hacia las periferias de París, Lyon y Toulouse. Los autores han manifestado la pertinencia de estos enfoques para el análisis de procesos que ocurren en las metrópolis de Estados Unidos y América Latina. 
dando paso a una ciudad configurada en torno a insularidades diversas (de producción, consumo, riqueza y marginalidad) y desconectadas entre sí (Prévôt Schapira, 2000; Janoschka, 2005). ${ }^{32}$

A continuación ubicaremos las experiencias del habitar reconstruidas durante el trabajo de campo en Nordelta conforme a tres ejes constitutivos de los desarrollos teóricos sobre la fragmentación o nueva segregación, la periurbanización o urbanismo afinitario: el temor y la búsqueda de seguridad como principales motivos residenciales, la constitución de comunidades purificadas, y la desolidarización hacia los sectores desfavorecidos.

\section{Las motivaciones residenciales}

Con base en nuestra experiencia sobre el terreno hemos considerado que las miradas que explican el fenómeno como reacción frente a la "inseguridad" y la violencia delictiva deben ser examinadas con detalle. ${ }^{33}$ Una focalización excesiva en el argumento "securitario" (si se nos acepta el neologismo) no nos permitiría dar cuenta de la heterogeneidad de propuestas presentes en el AMBA, ni de ciertas características peculiares que reviste un proyecto como el que nos ocupa. Nuestros interlocutores han expresado una variedad de razones para justificar la mudanza a Nordelta, algunas de ellas compartidas con los residentes de barrios cerrados o clubes de campo, y otras relativas a este emprendimiento.

32 Teresa Caldeira (1996), por ejemplo, sostiene que un nuevo modelo de segregación socioespacial rige en San Pablo desde la década de los ochenta y se ha superpuesto al patrón anterior cuyo fundamento se basaba en la oposición del centro (hábitat de clases medias y superiores) y la periferia (hábitat de clases populares). Las mutaciones recientes están generando una ciudad en la cual los diferentes grupos sociales se encuentran espacialmente próximos (ricos en la periferia y pobres en las áreas centrales), pero separados por muros y con escaso o nulo contacto entre sí. El término enclave fortificado que acuñó la autora pone de relieve que la fragmentación trasciende la función residencial, ya que se aplica a todos los espacios custodiados y amurallados, independientemente de sus usos efectivos (centros comerciales, complejos de oficina, parques temáticos, etcétera).

${ }^{33}$ En primer lugar porque no existen datos estadísticos que midan fehacientemente la inseguridad. Si bien los delitos denunciados parecen haber aumentado en las ciudades latinoamericanas en los noventa -en consonancia con los procesos de degradación socioeconómica que afectaron a su población-, los datos disponibles son deficientes. No obstante estamos de acuerdo con Amendola (2000) en que la sensación de inseguridad ha aumentado a un ritmo superior al de la violencia registrada. En segundo lugar, porque esta sensación no es exclusiva de los grupos favorecidos sino que afecta a todos los estratos sociales; en todo caso el desafío sería comprender las particularidades de las respuestas (Safa, 1999). 
En primer lugar, la decisión de partir hacia una urbanización cerrada siempre constituye una cuestión compleja en que intervienen muchos factores: la situación económica del grupo familiar, la historia personal de sus integrantes, la trayectoria residencial, la vivienda anterior y el lugar de origen, las oportunidades profesionales, las ansias de convivir con la naturaleza, la búsqueda de seguridad, la experiencia de algún episodio delictivo, etc., circunstancias cuyo peso es variable según cada entrevistado; "nosotros queríamos otra alternativa de vida, además nosotros tenemos cuatrillizos, en un departamento en Capital y con las chicas era muy complicado", nos comentaba un residente de Nordelta, contextualizando su decisión en una realidad familiar específica (Ricardo, 43 años, ingeniero, julio de 2005). ${ }^{34}$

En segundo lugar pensamos que la ponderación de factores económicos -reiteradamente ignorada por las investigaciones- ha sido cuidadosamente sopesada, máxime teniendo en cuenta que la nueva vivienda encarece el costo de vida ${ }^{35}$ Es evidente que para quienes optaron por la "migración" -representantes de una clase media-alta dependiente del crédito y de su capacidad de ahorro-, la evaluación del presupuesto disponible no ha sido un tema menor. En este sentido muchos entrevistados expusieron que se habían alejado de la ciudadcentro y de la periferia más onerosa (como Vicente López o San Isidro) para ganar en superficie y áreas verdes, y no necesariamente por lograr mayor seguridad. Si el distanciamiento posibilitó la ampliación o valorización del patrimonio y el contacto con la naturaleza, la extrema movilidad fue el precio pagado por la elección residencial (Girola et al., 2005a).

Tampoco podemos dejar de mencionar cierto pragmatismo economicista que suele llevar a una permanente evaluación de costos y

${ }^{34}$ Los nombres de nuestros interlocutores han sido cambiados para resguardar sus identidades. También por este motivo omitimos la referencia a sus barrios dentro de la ciudadpueblo. Respecto del perfil de los habitantes, cabe mencionar que si bien el proceso fue protagonizado por fracciones de las clases medias, como profesionales, empresarios, ejecutivos, deportistas, artistas, etc. (Svampa, 2005), coincidimos con Jaillet (2004) en que el periurbano no constituye un ámbito uniforme sino un mosaico que ofrece diferentes posibilidades según el nivel socioeconómico de los compradores. Si bien todos nuestros entrevistados se autorreconocieron como miembros de la clase mediaalta, no es menos cierto que ésta admite una significativa variedad de estatus y posiciones profesionales y que sus posiciones en la estructura social no han permanecido inmutables (Jaillet, 2004).

${ }_{35}$ Todos los entrevistados han reconocido este aumento de gastos, entre los cuales se incluyen: el mantenimiento de las casas (calefacción e iluminación de ambientes más grandes, acondicionamiento periódico de jardines y piletas, etc.), los costos de la movilidad (el peaje de las autopistas y la gasolina de los automóviles). 
beneficios -la mudanza es ante todo "una ecuación que cierra" (frase escuchada con asiduidad)-, tal como se grafica en la siguiente comparación:

las expensas del barrio no son caras para todo lo que te brinda [...] una expensa de 300 pesos aproximadamente, 300 y algo, te incluye una pileta, canchas de tenis, canchas de mini-fútbol, quinchos para hacer asados, todo eso está en el club house, y aparte bueno la bicisenda que es de todos. Yo tengo una amiga que vive en el centro en un departamento de 120 metros cuadrados y paga casi $\$ 700$ de expensas [Susana, 59 años, arquitecta, agosto de 2005]. ${ }^{36}$

En algunos casos el cortoplacismo se evidencia en la misma opción residencial -casi nunca se piensa para toda la vida-, ya que la conveniencia de vivir en un emprendimiento cerrado puede modificarse en función de inesperadas posibilidades laborales o del crecimiento de los hijos. ${ }^{37}$

En tercer lugar cabe destacar que los móviles residenciales han variado en función de la edad de nuestros interlocutores. En el caso de los mayores -matrimonios de jubilados o mujeres viudas- la decisión responde principalmente al deseo de adquirir una vivienda acorde a sus nuevas necesidades (más pequeña y en planta baja), previa venta de la casa familiar que ha quedado demasiado grande. ${ }^{38}$

No es nuestra intención subestimar la búsqueda de seguridad en las expectativas de los habitantes, sino restituir esta dimensión del habitar en la trama de circunstancias y motivaciones que conducen al

${ }^{36}$ Este pragmatismo también se expresa en una suerte de "resignación": “...no es que yo prefería la urbanización cerrada, yo viví en urbanización abierta y me pareció divino, y la idea de cerrarme como en un gueto no era mi idea. Pero bueno, frente a que tenemos una situación del país muy complicada, me parece por lo menos estos primeros años de la vida, donde los chicos son muy pequeños, está bien esto" (Agustina, 32 años, profesora de gimnasia, julio de 2005). En reiteradas ocasiones los residentes han manifestado esta vivencia: tras una experiencia de vida en barrios abiertos, el cierre parece "soportarse" como una imposición, como una adaptación a circunstancias externas.

37 Las ventajas que las urbanizaciones ofrecen a los niños se revierten cuando crecen y la distancia se convierte en un obstáculo para sus actividades cotidianas (salidas nocturnas y estudios universitarios).

${ }^{38}$ La mudanza de hombres y mujeres de la tercera edad hacia estas urbanizaciones suele estar generalmente ligada a relaciones de parentesco, ya que suelen establecerse en el mismo emprendimiento que sus hijos y nietos o en uno próximo. Por cuestiones de espacio no nos referiremos aquí a otra importante motivación residencial: el deseo de revivir en la nueva urbanización la experiencia del barrio o pueblo de la infancia o la adolescencia. Para un análisis del peso que reviste este barrio evocado en la memoria de los residentes remitimos a otros trabajos de nuestra autoría (Girola, 2005b). 
traslado. Es indudable que la protección que ofrecen los emprendimientos es un servicio valorado, pero de ningún modo agota la explicación del fenómeno. ${ }^{39}$ En este sentido no está de más advertir que la vigilancia provista no se considera un remedio infalible sino un atenuante de la violencia que se registra en la ciudad abierta. Además, la presencia de guardias privados puede ser objeto de una valoración contradictoria. Si bien poseen mejor imagen que la policía bonaerense -institución desprestigiada y a la que con razón se supone participante del delito-, los residentes se distancian de miradas ingenuas y reconocen que los sistemas de seguridad presentan fallas (los episodios de raterismo y vandalismo infantil dentro de las urbanizaciones son frecuentes, al igual que las huelgas del personal de vigilancia o su falta de capacitación).$^{40}$

Para finalizar agregaremos a las motivaciones generales mencionadas los argumentos específicos del caso analizado. Una cita etnográfica resulta esclarecedora: “¿Por qué decidieron mudarse a Tigre?”, se preguntó. "No fue Tigre, fue Nordelta el proyecto lo que nos gustó, la infraestructura, los servicios, es interesante, a mí me da confianza y no me llevé ninguna sorpresa" (Valentina, 27 años, profesora de yoga, agosto de 2005). La integralidad y la seriedad son "categorías nativas" que suelen repetirse a la hora de explicar la inclinación por la ciudadpueblo. Mientras en los barrios cerrados sin espacios comunes la vigilancia es el principal servicio y por ende un fuerte pretexto residencial, en una gran estructura la seguridad debe relacionarse con otros beneficios. Así, las propuestas residenciales, comerciales, educativas y recreativas alejan a la ciudadpueblo de los simples barrios perimetrados, al tiempo que conjuran las sensaciones de aislamiento y encierro que puede generar este tipo de viviendas: "si bien Nordelta son barrios encerrados en sí mismos, están integrados en una comunidad con una estructura de ciudad que tiene espacios públicos y semipúblicos [...] Por lo cual no era el caso de Pilar, que son urbanizaciones en medio

${ }^{39}$ La investigadora brasileña Patriota de Moura (2003) ha llegado a conclusiones similares a partir de su estudio etnográfico en "condominios fechados" de Goiânia. Asimismo Teixeira de Andrade (2004) cuestiona los enfoques que visualizan el auge de las comunidades cerradas por razones de seguridad. Tales posturas no podrían dar cuenta del avance del fenómeno en ciudades grandes, medianas o pequeñas reconocidas como seguras.

${ }^{40}$ En Nordelta han ocurrido robos en los barrios y en el centro comercial. Asimismo los puestos de vigilancia que se disponen en el camino Bancalari-Nordelta no han logrado evitar los ataques con piedras que sufren los automóviles al ingresar o salir de la ciudadpueblo, y cuyos resultados incluyen vidrios rotos, carrocerías abolladas y conductores con heridas cortantes. 
del campo. Acá es una integración no sé si total, al menos parcial, con los barrios de alrededor" (Javier, 44 años, periodista, junio de 2005).$^{41}$

La opción por el producto Nordelta es indisociable de la confianza que su responsable genera en los residentes. El nombre de Eduardo Constantini ha vuelto una y otra vez en los relatos recogidos, ya sea como una personalidad emprendedora y protectora, como garante de la continuidad del proyecto, o como un propietario y vecino más de la ciudadpueblo. ${ }^{42} \mathrm{~A}$ continuación veremos que este hombre de negocios y "demiurgo" de Nordelta está comprometido a otorgar al emprendimiento una identidad cultural basada en el arte y en difundir la imagen de una comunidad nordelteña cohesionada y sin conflictos.

\section{De la prédica comunitaria a la comunidad en acción: disoluciones y resquebrajamientos}

"Lo más importante de Nordelta es su alma"

Eduardo Constantini

La comunidad constituye uno de los conceptos básicos en torno a los cuales ha girado la narrativa de la condición humana moderna y premoderna. Desde las primeras conceptuaciones de F. Tönnies a la noción de folk society elaborada por R. Redfield, la comunidad puede definirse

${ }^{41} \mathrm{El}$ encierro y el aislamiento, asociados a la imagen de gueto, los viven los residentes con incertidumbre, especialmente por sus posibles efectos en sus hijos. Por esta razón suelen poner en práctica estrategias para salir de la "burbuja": utilizar transportes públicos, realizar compras fuera del circuito de shopping center e hipermercados, visitar la ciudad de Buenos Aires con los niños, fomentar en ellos acciones solidarias con los sectores populares del entorno. Asimismo es común que los habitantes equiparen con sus experiencias en el "afuera" las condiciones de encierro y relativa homogeneidad sociocultural de los emprendimientos: "Llegó un momento en que me di cuenta que vivíamos en Palermo Viejo en un barrio privado virtual, donde las ventanas tenían rejas, donde los chicos salían de la casa sólo para ir a un colegio, donde todos los padres eran similares a lo que éramos nosotros" (Javier, 44 años, periodista, junio de 2005).

${ }^{42}$ La familia Constantini está estrechamente vinculada a Nordelta: un pariente político lidera el equipo de abogados de Nordelta S. A.; el club y la revista del emprendimiento también están en manos del "clan", y la esposa del empresario tiene a su cargo una de las inmobiliarias que comercializan lotes. La figura de Eduardo Constantini (quien posee su casa en el barrio más caro y cuyo hijo asiste a un colegio del emprendimiento) siempre ha sido objeto de comentarios para los entrevistados: ya sea por el accidente en un lago nordelteño que casi le cuesta la vida, por su reciente divorcio y su frecuente aparición en las revistas, o por sus exitosos negocios. Como coleccionista de arte ha devenido fundador del Museo de Arte Latinoamericano de Buenos Aires; también es el dueño de la lujosísima torre de viviendas porteñas Gran Bourg. 
por tres características básicas: unidad, homogeneidad y mismidad. ${ }^{43}$ Luego de un destierro prolongado producto de los procesos de emancipación y autonomía individuales que caracterizaron al capitalismo industrial, estaríamos asistiendo, desde la perspectiva de ciertos autores, al renacimiento de comunitarismos de cortes diversos que se han desarrollado como reacciones previsibles frente a una época que multiplicó las fuentes de temor, de incertidumbre, inseguridad y desprotección (Bauman, 2002: 192). Este autor se ha concentrado especialmente en las comunidades de base residencial, vecindarios que se viven como "entidad homogénea y armoniosa en su interior, purificada de toda sustancia extraña e indigerible, con todos los puntos de acceso cuidadosamente vigilados, controlados y protegidos, pero pesadamente armada en el exterior y recubierta por una coraza impenetrable" (Bauman, 2002: 195). Pero si como ya hemos mencionado, la búsqueda de seguridad entre los residentes de Nordelta es indudable, una visión meramente defensiva corre el riesgo de hacernos perder de vista otras interesantes características de los procesos de constitución de comunidad. ${ }^{44}$

En esta sección nos detendremos en algunas facetas de lo que denominamos la prédica comunitaria, vale decir, en la difusión y legitimación -mediante una serie de dispositivos institucionales- de un discurso capaz de generar identidad y cohesión en la ciudadpueblo. En primer lugar, el cumplimiento del plan director ideado por los desarrolladores y al que ya nos hemos referido es la carta fundacional que brinda confianza a los residentes y credibilidad en el proyecto, dos pilares fundamentales para el florecimiento de la comunidad. Este plan maestro también incluye la gestación de una esfera comunicacional a través de la red NDNET, mediante la cual se puede acceder -on line las 24 horas del día- a las empresas, universidades, colegios, clubes y barrios. ${ }^{45}$

${ }^{43}$ La comunidad también puede definirse con otros atributos: distinción (división exclusiva y disyuntiva entre "nosotros" y "ellos"), pequeñez (lo que permite una comunicación intensa entre sus miembros), autosuficiencia entendida en términos de aislamiento (Bauman, 2003: 18).

${ }^{44} \mathrm{La}$ seguridad a la que aspiran los entrevistados reconoce varios niveles: la seguridad económica que les brinda la inversión realizada mediante la adquisición del lote y la vivienda; la seguridad corporaly doméstica que requiere una permanente vigilancia de las fronteras entre el cuerpo-casa-barrio y el afuera; la seguridad ecológica y ambiental que les ofrece vivir en un medio no contaminado como Nordelta.

${ }^{45}$ Además permitirá el acceso a múltiples servicios: desde la participación en videoconferencias emitidas desde cualquier establecimiento hasta la posibilidad de reservar turnos en clubes, firmar boletines escolares, o "asistir" a reuniones virtuales de padres, de consorcio o de la comisión del club. 
En segundo término, la revista Nordelta apuntala permanentemente la constitución de una comunidad de contenido cosmo-visional (Delgado Ruiz, 2002: 10) basada en compartir valores: "El nordelteño es un ser esencialmente sano, sociable, alegre y esperanzado. Es quien confía en un proyecto, aquel que se regocija en el canto de los pájaros, la pureza de sus lagos, la aventura de navegar. Quien cultiva la elección del entorno que privilegia el verde, el bienestar, el deporte para una vida más plena en la naturaleza donde construirá su casa”, según afirmaba un comentario editorial. ${ }^{46} \mathrm{La}$ obsesión homogeneizante que se evidencia desde la perspectiva "oficial" parece haber dado sus frutos. ${ }^{47}$ Los resultados que arrojó una encuesta sobre cuál debería ser el patronímico de cada barrio no dejó lugar a dudas, pues fueron evidentes los fuertes mecanismos de apropiación del emprendimiento: "todos somos nordelteños". 48

En tercer lugar, los acontecimientos deportivos y socioculturales constituyen recursos que unen a la comunidad hacia adentro, dotándola de límites simbólicos específicos y permitiendo a sus integrantes experimentar cierta coherencia identitaria (Delgado Ruiz, 2002: 167): de las galas líricas a los torneos deportivos (del barrio o de la ciudadpueblo), de los campeonatos de bridge a la bicicleteada por el Día del Medio Ambiente, de las regatas a las exposiciones pictóricas y a los actos de beneficencia que veremos más adelante. Arte, deporte y naturaleza aparecen como una tríada que mediatiza las relaciones sociales internas, con poderosos efectos terapéuticos y reparadores. En este sentido, el principal mentor del emprendimiento se ha comprometido a "diagramar actividades que busquen afianzar a Nordelta como una comunidad", pues aspira a que sea algo más que una mera yuxtaposición de barrios cerrados. ${ }^{49}$

${ }^{46}$ Revista Nordelta, año 3, núm. 12, agosto-septiembre de 2005. Las dos publicaciones que circulan en Nordelta, a pesar de las diferencias comentadas, apoyan la prédica comunitaria. En sus notas se resaltan los valores esencializados que definen a los habitantes: solidaridad, conciencia social, integración hacia adentro y afuera, colaboración, respeto por la diferencia, etcétera.

${ }^{47}$ Con "perspectiva oficial" nos referimos al relato difundido por los desarrolladores, las instituciones educativas, el Club Nordelta y la Fundación, en suma, por las principales instituciones interesadas en el emprendimiento.

${ }^{48}$ Las justificaciones para tal elección son elocuentes: "si en la ciudad son todos porteños aunque vivan en Once o Barrio Norte, acá somos nordelteños aunque vivamos en Caletas o Castores", "nordelteño es unificador", "hay que evitar caer en denominaciones que sólo sirven a la individualidad y no a la unidad comunal".

${ }^{49}$ Periódico de los Vecinos de Nordelta, edición correspondiente al 07/12/2005. Para su mentor, la formación de tal comunidad no debe ser librada al azar sino el "producto de algo estructurado y organizado". Resulta notable la aplicación de ciertos principios de 
Lo expuesto hasta aquí nos inclina a pensar que lejos de un gueto voluntario (Bauman, 2003), Nordelta se presenta como una verdadera ciudad-patria, que en los términos irónicos de Delgado Ruiz es un miniestado ciudadano que procura suscitar la adhesión emotiva de sus súbditos (Delgado Ruiz, 1998: 99). La prédica comunitaria implica, entonces, la producción de significados que buscan gestar identidad y comunidad en un emprendimiento que se ha establecido en espacios vacíos y a partir del desplazamiento de sujetos con procedencias y trayectorias de vida heterogéneas. Con el objetivo de insuflar un sentido de pertenencia en las "nuevas generaciones", las instituciones educativas organizan recorridos escolares por las distintas áreas de Nordelta, visitas guiadas que suelen incluir una charla con alguno de sus desarrolladores para así interiorizar a los niños en el origen y las características de "su ciudad" ${ }^{50}$ Esta producción significante no solamente apunta a la exaltación de la figura del "nordelteño modelo", pues también constituye un férreo control político sobre los sentidos sociales que se asocian al lugar (Delgado Ruiz, 1998: 100).

En esta misma dirección debemos comprender la exaltación de la figura de los pioneros de la ciudadpueblo, la placa conmemorativa de la mudanza de sus primeros vecinos en 1999 (presentados como heroicos aventureros) y otros rituales que intervienen en la construcción de la utopía comunitaria. ${ }^{51}$ Los residentes suelen experimentar esta nueva residencia como una suerte de posesión: la experiencia nordelteña se vive como la gestación de una comunidad de la que son protagonistas, de un grupo humano dueño de su tiempo y de su espacio -una sensación nunca percibida en la ciudad tradicional. ${ }^{52}$

funcionamiento empresarial a la gestación de una "cultura urbana". Para que tome cuerpo la deseada comunidad, Constantini convoca permanentemente a algunos residentes famosos del emprendimiento, entre los cuales hay quienes pueden llevar la prédica comunitaria a niveles épicos: "Como hizo Augusto en la Roma antigua, Eduardo Constantini llamará a algún Virgilio que escriba algún argumento, por qué no. Pero tendrá que haber un espíritu que vaya gestándose. Habrá que crear una cultura Nordelta [...] Que haya un mito estructurante que vaya dando identidad es precondición”, sostenía un reconocido psicoanalista (revista Nordelta, año 2, núm. 6, agosto-septiembre de 2004).

${ }^{50}$ Los colegios que funcionan en Nordelta también se ocupan de la constitución de la comunidad en términos religiosos. Dos de las tres instituciones que allí actúan difunden valores católicos mediante la celebración de misas, actos de bendición, acciones litúrgicas con motivo de la Semana Santa y otros acontecimientos que animan a Eduardo Constantini a querer reemplazar la capilla de la ciudadpueblo por una iglesia.

${ }^{51}$ En el aniversario del primer año se organizó una reunión que representó -con una estética que apeló a la tradición- la idea de "fundación" de la ciudad comunidad.

${ }^{52}$ Las exhortaciones a la acción comunal son moneda corriente: "Tenemos hoy la oportunidad de moldear nuestro futuro como sociedad, aprovechémosla para forjar una cultura ciudadana digna de ser imitada" arengaba el gerente de Nordelta en una 
Pero nuestro análisis no puede dejar de resaltar que Nordelta está lejos de ser ese universo de entendimiento común y natural que sueñan los artífices de la prédica comunitaria. De este modo, consideramos que el sentido de comunidad de los vecinos unidos por lazos de solidaridad e integración se presenta, más que como una experiencia, como una aspiración, como un anhelo constantemente quebrantado por los conflictos y disputas que se generan dentro de esta forma de habitar.

En primer término, la esfera vecinal se construye de modo simultáneo y contradictorio en torno a tres polos principales: los encuentros aleatorios, la sociabilidad voluntaria y la sociabilidad padecida. Por un lado, los vecinos protagonizan encuentros inesperados y efímeros que incluyen las salutaciones de rigor, y ciertos diálogos ritualizados sobre las novedades familiares, las actividades recreativas, el intercambio de favores. Por otro lado, se entablan en los espacios compartidos relaciones sociales potencialmente integrables a redes electivas o afinitarias (amigos y familiares). Por último, los vecinos pueden mantener relaciones de desconocimiento o indiferencia, y padecer lazos vinculados a conflictos derivados de la convivencia.

Por otro lado, la gestión de las diversas áreas residenciales convierte a los vecinos en socios, ya que los barrios de Nordelta funcionan como sociedades anónimas: "El directorio de cada barrio, el consejo y el tribunal de disciplina se ocupan de la administración interna, de los espacios en común, los contratos firmados, las multas por obras mal hechas, los animales sueltos, la morosidad" (Javier, 44 años, periodista, junio de 2005). Todas las tensiones que se producen en esta esfera repercuten negativamente en las relaciones vecinales, ya que ambas constituyen dos facetas del habitar estrechamente vinculadas.

Por último aludiremos brevemente a lo que se presenta como un conflicto abierto que enfrenta a los vecinos con la desarrolladora. Desde 2004 los habitantes han comenzado a reclamar participación en la Asociación Vecinal Nordelta (AVN), el principal órgano de "gobierno" de la ciudadpueblo, con el propósito de controlar las que consideran medidas arbitrarias y no consensuadas de Nordelta S. A. ${ }^{53}$ El malestar

nota editorial de la revista Nordelta (año 3, núm. 10, abril-mayo de 2005), destacando el carácter pedagógico y ejemplar de la tarea.

${ }^{53} \mathrm{La}$ AVN se encarga de la gestión de las actividades compartidas y del mantenimiento de todos los espacios comunes, la seguridad perimetral, la forestación, los lagos, la avenida troncal. Su estructura incluye personal cuyos salarios -equiparados con los de Consultatio S. A.- se solventan con las expensas de los residentes. El directorio de la AVN toma las principales decisiones que afectan al emprendimiento. 
de los vecinos se expuso en algunas reuniones con E. Constantini, quien finalmente admitió que ingresaran dos propietarios y un representante de las áreas comerciales al directorio de la AVN. Sin embargo el descontento no ha menguado: Nordelta S. A. conserva cuatro votos y tres de los vecinos y comerciantes. Esta situación se repite en las asociaciones civiles que administran cada barrio, donde los desarrolladores conservan una mayoría de las acciones y así suelen imponerse sobre los propietarios. En 2005 la desarrolladora aceptó que se conformara un Consejo Vecinal Nordelta (CVN) integrado por representantes de los barrios, los comercios y las escuelas; una suerte de órgano consultivo de las decisiones que finalmente recaen en la AVN.

Como vemos, la prédica comunitaria no ha podido acallar las disputas, disensos y apropiaciones conflictivas de los vecinos. La constitución cívico política de la ciudadpueblo admite críticas y experimentaciones y acepta acuerdos frágiles como el producto de negociaciones siempre tensas.

\section{La retórica de la solidaridad}

Consideramos que el trabajo etnográfico que hemos realizado hasta el momento nos autoriza a examinar cualquier aplicación mecánica del concepto de desolidarización al caso escogido y a profundizar, críticamente, en los lazos establecidos entre los emprendimientos cerrados y los barrios desfavorecidos.

En primer lugar, huelga reiterar que la mayoría de los individuos periurbanos bonaerenses abandonaron sus elegantes barrios porteños (Belgrano, Barrio Norte, Palermo) en busca de conjuntos situados en suburbios deteriorados, fuertemente poblados por villas miseria y asentamientos populares. Todos los entrevistados se han referido a la degradación ambiental y socioeconómica que rodea Nordelta, frente a la cual se posicionan como "privilegiados" ( $s i c$ ). Por esta condición, los residentes justifican y aprueban los impuestos municipales, especialmente si se traducen en obras que benefician al partido (escuelas y hospitales públicos, plazas y caminos), incluso si no las usan. ${ }^{54} \mathrm{En}$

${ }^{54}$ Para el año 2006 se prevé un aumento de los impuestos a raíz de ajustes en los costos de los salarios y las obras públicas, pero los entrevistados se han mostrado satisfechos con la gestión tigrense, ya que se ven las mejoras y además el trato en la intendencia es amable. Por el contrario, hay una fuerte disconformidad con los altos gravámenes que pagan al Gobierno de la Provincia de Buenos Aires (rentas y permisos de construcción). 
segundo término, es recurrente la procuración de servicios mediante proveedores cercanos, no solamente por una cuestión de proximidad sino por la expresa voluntad de contribuir al progreso de la localidad: "Vos pensá que estas casas requieren de personal de mantenimiento, si eso se puede, permite darle posibilidades de trabajo a la gente que vive en la zona" (Salvador y Nelly, 66 años ambos, ingeniero y química ya jubilados, julio de 2005). ${ }^{55}$ Por último, no hemos registrado hasta ahora reclamos secesionistas en las urbanizaciones del GBA, aunque algunos proyectos polémicos apuntan a autonomizar los mecanismos de regulación de la convivencia interna. ${ }^{56}$

Pero nuestro cuestionamiento de los desarrollos teóricos sobre la desolidarización a la luz del caso vernáculo estaría incompleto sin un primer acercamiento a un campo de acción que constituye un elemento significativo de la residencia en Nordelta: la relación con los "otros externos" mediante una gestión institucional de la alteridad que asume la forma de beneficencia privada.

La Fundación Nordelta nació en el año 2002 como una organización sin fines de lucro cuya "misión es mejorar la calidad de vida de los barrios carenciados"; $;{ }^{57}$ operando conforme a "un modelo de interrelación comunitaria innovador y replicable" -nótese nuevamente la vocación pedagógica- que permite a una comunidad, a partir de sus recursos, mejorar la calidad de vida de sus poblaciones vecinas. Por consiguiente, sus acciones se dirigen al populoso barrio Las Tunas..$^{58}$ Un miembro de la Fundación sintetizaba: "Constantini es un hombre muy visionario que vio la fractura social, el abismo que hay entre una comunidad y otra, la idea es ser un puente entre ambas comunidades, que se pueda reparar esa fractura social a través de valores como la

${ }^{55}$ Hemos relevado esta situación en otras urbanizaciones cerradas de Tigre y en Pilar. Con relación a este punto cabe destacar que los residentes adoptan una visión optimista que resalta los impactos positivos del fenómeno, sin tener en cuenta sus repercusiones negativas.

${ }^{56}$ Desde el año 2005 se encuentra en proceso una ley que otorgaría mayor poder a los consejos de disciplina de cada emprendimiento, quienes podrían aplicar sanciones que llegarían incluso a la expulsión de los propietarios (en oposición al derecho de propiedad reconocido por la Constitución Nacional).

${ }^{57} \mathrm{La}$ información vertida ha sido reconstruida a partir de folletos de la Fundación, de la revista Nordelta y de la página web de la ciudadpueblo.

${ }^{58}$ Las Tunas se ubica en la localidad de General Pacheco del partido de Tigre, al suroeste de Nordelta. Con 25000 habitantes, el barrio muestra indicadores alarmantes: tierras inundables, agua de pozo presumiblemente de napas contaminadas por frigoríficos de la zona, carencia de redes de drenaje, $60 \%$ de desempleo, altos índices de deserción escolar y de desnutrición infantil, ausencia de escuelas de oficio, falta de espacios y actividades para jóvenes. 
solidaridad, la participación, el compromiso" (registro de campo, julio de 2004). Un promotor inmobiliario del emprendimiento fue mucho más pragmático respecto de las intenciones de la Fundación: "cumple una función de contención [...] yo te doy esto, así que no me jodás" (registro de campo, abril de 2004). Por cierto, esta concentración de la beneficencia en la pobreza cercana parece una constante en el ámbito de las urbanizaciones cerradas, tendencia que se ha intensificado después de la crisis socioeconómica que tuvo su epicentro en el periodo 2001-2002.59

Con un staff predominantemente femenino, la institución opera valiéndose de voluntarias y delegadas barriales que colaboran en las áreas de salud y educación, desarrollo comunitario, inserción laboral; asimismo organiza actividades para difundir sus tareas y recaudar fondos (kermés para el Día del Niño, encuentros corales, feria de regalos de Navidad, ciclo de actividades infantiles, desayuno de bienvenida a propietarios, etcétera) ${ }^{60}$

Una mirada al área de inserción laboral puede ser esclarecedora de las modalidades de intervención de la Fundación. Allí se brindan cursos de capacitación actitudinal y aptitudinal para potenciar las habilidades de quienes buscan empleo. Una vez formados, los trabajadores pueden sumarse a una base de datos que articula la demanda de Nordelta con la oferta de Las Tunas y facilita así las relaciones entre el empleado y el empleador (un propietario o una empresa). Pero la intermediación de la Fundación no termina allí; también se encarga de verificar las referencias y hacer un seguimiento laboral con el fin de

${ }^{59}$ Los country club de Pilar y Escobar colaboran en los comedores y merenderos de las localidades carenciadas de estos partidos (Derqui, Manuel Alberti o Garín). A veces la ayuda es todavía más focalizada: Highland Park, por ejemplo, concentra sus acciones en el barrio contiguo, Los Cahorros: "Si uno va a su casa y en el camino pasa digamos por una villa y probablemente la mujer que limpia en tu casa vive allí y el marido es tu jardinero, es lógico que quieras ayudar", nos comentaba un funcionario de Pilar residente en un barrio cerrado (registro de campo, marzo de 2005). Que este tipo de iniciativas se fortaleciera durante la aguda crisis de 2001-2002 no parece haber sido "inocente" ni casual, pues quizás apuntara a atenuar una coyuntura conflictiva: en aquel periodo algunos medios habían hecho correr rumores de los posibles ataques de los excluidos del GBA a los countries.

${ }^{60}$ La Fundación también cuenta, para el sostenimiento de sus programas, con los aportes de Carrefour, Banco Francés, Fundación Renault, Laboratorio Boehringer Ingelheim, Pepsi, Grupo Telecom, Mac Donald's, Petrobrás, etc. Las campañas benéficas de las empresas nacionales y multinacionales -en sintonía con la moda de la responsabilidad social de los empresarios-casi nunca están desprovistas de intereses estratégicos: crear fidelidad hacia la marca, mejorar su imagen, aumentar las ventas (diario Clarín, Suplemento Económico, 04/07/1999). 
mejorar la predisposición frente al trabajo. El curso sobre servicio doméstico, por ejemplo, se propone "fortalecer los conocimientos y habilidades de las mujeres en el manejo del hogar". La institución asegura que ha llegado a colocar a 200 personas mediante este sistema. ${ }^{61}$

Resulta imprescindible relacionar el surgimiento de este tipo de organizaciones de la sociedad civil (ONG, asociaciones barriales, grupos comunitarios, etc.) con la redefinición del rol regulador del Estado en las sociedades latinoamericanas sometidas a procesos de ajuste estructural. En este marco de crisis de los modelos clásicos de protección social se ha legitimado un discurso público que presenta la actuación de estas instituciones como una alternativa moderna capaz de garantizar los derechos sociales de manera competitiva y eficaz, una opción a mitad de camino entre las rigideces propias de la burocracia estatal y el afán meramente lucrativo del mercado (Da Silva Telles, 2004: 130) ${ }^{62}$

En nuestro caso específico es necesario contextualizar la "nueva filantropía” en el proceso de consolidación de un Estado neoliberal asistencialista que transfirió a terceros buena parte de los servicios sociales no rentables, mientras privatizaba los que contaban con una potencial demanda solvente (Grassi, 2003: 282) ${ }^{63} \mathrm{Al}$ plantear sus objetivos como si se tratara de una "misión", la Fundación Nordelta ejemplifica una de las formas en que se constituyó la cuestión social en la Argentina de los noventa: las políticas sociales que reconocían e impartían derechos a los ciudadanos fueron en buena medida sustituidas por

${ }^{61}$ Empleada doméstica, electricista, plomero, costurera, cocinera, jardinero, piletero, pintor, carpintero, chofer, parrillero, albañil, handy-man, paseador de perros, limpiavidrios en altura, cuidadora de niños y ancianos. Se trata de programas cuyo alcance es restringido si se toman en cuenta los altos índices de población de Las Tunas, que nos remiten a los análisis de Teresa Caldeira para el caso paulista: las clases medias altas residentes en conjuntos cerrados requieren los servicios de trabajadores subalternos, con quienes mantienen relaciones ambiguas de dependencia y desconfianza (Caldeira, 1996: 161).

${ }^{62}$ Los integrantes de la Fundación sostienen que ésta no fomenta el asistencialismo sino que ayuda a los pobladores de Las Tunas a desarrollarse y mejorar su calidad de vida. Si bien los residentes entrevistados evaluaron diferenciadamente las tareas de la Fundación (de la valoración positiva a la indiferencia, del desconocimiento a la duda), todos parecen participar en sus acciones desde la distancia, sin intervenir mayormente en sus programas.

${ }^{63}$ Cruzadas solidarias, llamados a la solidaridad, apertura de cuentas bancarias para donaciones, concursos telefónicos, etc. Como observa Grassi (2003), ni por su magnitud ni por su impacto, estas acciones que habían sido desestimadas con el desarrollo del carácter social del Estado merecerían mayor atención. Sin embargo, en el ámbito de los emprendimientos cerrados la emergencia de un sentido privado y voluntario de la solidaridad aparece como un aspecto relevante de la experiencia de habitar, junto con la naturaleza, la seguridad y la práctica del deporte. 
las obligaciones morales de los particulares (Grassi, 2003: 283), en este caso por una "comunidad nordelteña" entendida en términos amplios (propietarios, instituciones y empresas). "Si queremos crear una comunidad nueva, no podemos dejar de lado a nuestros vecinos", afirmaba en la revista Nordelta un integrante de la Fundación. ${ }^{64}$

La Fundación constituye así uno de los principales soportes de la prédica comunitaria, que como dijimos, incluye también a otros dispositivos sociales de la ciudadpueblo (master plan, revista Nordelta, instituciones educativas). La eficacia simbólica de sus acciones se advierte por ejemplo en lo que se reconoce como el festejo más importante del emprendimiento: la Cena Anual Solidaria, organizada por la Fundación. ${ }^{65}$ Hacia adentro esta noche solidaria persigue el explícito objetivo de crear un sentido de pertenencia entre los vecinos, puesto que como toda fiesta constituye "un recurso mediante el cual una comunidad cualquiera se brinda la posibilidad de hacer real su ficción compartida de unidad" (Delgado Ruiz, 2002: 164). Hacia afuera se promueve una retórica de la solidaridad que aspira a "derribar muros", "establecer puentes", "abrir puertas", vale decir, a ignorar los contrastes sociales que se agudizaron en el GBA de la mano de estos emprendimientos.

Siguiendo a Da Silva Telles cabe preguntar si con este auge de la beneficencia privada estamos acaso frente a programas que diluyen el problema de la responsabilidad pública y que reactualizan bajo una forma renovada un viejo modus operandi: la gestión filantrópica de la pobreza o, lisa y llanamente, el retorno a la caridad. Si se vacía de contenido político la cuestión social, ésta queda reducida al ámbito de la intervención comunitaria y a un sentido estrictamente moral (Da Silva Telles, 2004: 140). Estimamos entonces que tanto la plática solidaria de la Fundación como la escenificación de sus acciones (tanto mediante las actividades que organiza como por medio de sus publicaciones anuales) pueden obliterar -en el ágora privada de la ciudadpueblo- discusiones sobre la solidaridad entendida en términos de justicia social, redistribución de riquezas y obligación del Estado, al tiempo que refuerzan vivencias comunitarias. De esta forma, no extra-

${ }^{64}$ Revista Nordelta, año 3, núm. 12, agosto-septiembre de 2005.

${ }^{65}$ La actividad suele realizarse en una carpa montada en las áreas deportivas de algún colegio nordelteño. El primero tuvo lugar en 2004; al segundo (2005) concurrieron 700 personas que presenciaron un espectáculo de circo, una subasta de vinos y sorteos de premios. La presencia del intendente de Tigre es infaltable en la mesa principal, junto a Eduardo Constantini y otros empresarios. Todo lo recaudado durante esa noche se deriva a los programas sociales de la Fundación. 
ña que entre los residentes predominen miradas que atribuyen a características individuales, como la mala formación, la falta de cultura del trabajo o de planificación familiar, carencias colectivas que resultan de procesos sumamente complejos.

\section{A modo de cierre}

El aumento de conjuntos residenciales con seguridad habitados por las clases medias-altas constituye una tendencia urbana actual que ha sido captada con interés por los medios de comunicación, los especialistas en urbanismo y los investigadores sociales de las disciplinas más diversas (sociólogos, geógrafos, antropólogos, economistas, expertos en derecho). En Argentina, el auge de urbanizaciones cerradas en la Región Metropolitana de Buenos Aires ha concitado la atención de la prensa, la cual se ha transformado rápidamente en un importante ámbito de construcción de imágenes y discursos -estereotipados pero de amplia difusión y aceptación social- sobre los emprendimientos y sus habitantes. Mientras que desde la perspectiva de los comercializadores y los empresarios se celebró su instauración como resultado de la búsqueda de una mejor calidad de vida, sus detractores condenaron el establecimiento de fronteras materiales que consolidaban una ciudad fragmentada expulsando el peligro hacia el otro lado del muro.

En este artículo hemos preferido distanciarnos de las miradas simplificadoras y de los juicios condenatorios mediante un enfoque etnográfico que nos permitiera analizar las prácticas y representaciones de quienes eligieron vivir en una de las versiones más singulares que adopta el fenómeno en la aglomeración de Buenos Aires: la ciudadpueblo Nordelta.

De este modo hemos contextualizado el caso en el seno de procesos de transformación urbana que afectan a la periferia de la RMBA y hemos procurado comprender las múltiples perspectivas de los sujetos comprometidos en la constitución del universo estudiado. Sin embargo, así como hemos recabado los puntos de vista de nuestros interlocutores, no podemos dejar de lado los graves procesos de segregación socioespacial vigentes en la RMBA, y la existencia de situaciones residenciales que expresan un acceso desigual a los bienes y los servicios urbanos.

El enfoque adoptado nos ha permitido ahondar en ciertos aspectos constitutivos de los planteamientos teóricos fundados en la noción 
de fragmentación. A partir del caso trabajado hemos repensado los siguientes ejes:

- La búsqueda de seguridad debe ser descartada como principal factor explicativo de la mudanza hacia una urbanización como Nordelta y recentrada en una compleja trama de motivos residenciales.

- Las tan ansiadas homogeneidad y armonía comunitaria deben ser matizadas mediante el reconocimiento de ciertos procesos simultáneos y contradictorios: la constitución y disolución de la comunidad "nordelteña", la tensión permanente entre la cohesión y el conflicto (tácito o explícito, pero en todo caso siempre latente), entre el consenso y el disenso.

- La desolidarización debe ser examinada a partir de un análisis de los vínculos sociales que se establecen entre los residentes del emprendimiento y los barrios carenciados circundantes, atendiendo especialmente a las acciones benéficas que desarrolla la Fundación Nordelta.

Es indudable que la proliferación de este tipo de emprendimientos continuará generando controversias entre los académicos, los funcionarios y los ciudadanos que animan las urbes contemporáneas. La polémica tiene razón de ser, ya que, al privatizar la trama urbana, estos conjuntos amenazan ciertos ideales constitutivos de la modernidad urbana, más específicamente, las posibilidades de consolidar ciudades democráticas e igualitarias. El debate sigue abierto y nuestra intención no ha sido llegar a respuestas definitivas sino iniciar un camino de reflexión y profundización sobre los sentidos sociales del fenómeno, un recorrido de articulación teórica y una sistemática indagación empírica.

\section{Bibliografía}

Amendola, Giandomenico (2000), La ciudad posmoderna. Magia y miedo de la metrópolis contemporánea, Madrid, Celeste.

Bauman, Zigmunt (2003), Comunidad. En busca de seguridad en un mundo hostil, Buenos Aires, Siglo XXI.

- (2002), Modernidad líquida, Buenos Aires, Fondo de Cultura Económica.

Bourdieu, Pierre y Loic Wacquant (1995), Respuestas. Por una antropología reflexiva, México, Grijalbo. 
Caldeira, Teresa (1996), "Un novuea modèle de ségrégation spatiale: les murs de Sao Paulo", Revue Inernationale de Sciences Sociales, núm. 147.

Da Silva Telles, Vera (2004), "La sociedad civil entre la ciudadanía y la filantropía", en José Luis Coraggio y Claudia Danani (comps.), Política social y economía social. Debates fundamentales, Buenos Aires, Altamira, pp. 127-142.

Ciccolella, Pablo (1999), “Globalización y dualización en la Región Metropolitana de Buenos Aires: Grandes inversiones y reestructuración socioterritorial en los años noventa”, Eure, vol. 25, núm. 76, pp. 5-27.

Delgado Ruiz, Manuel (2002), Disoluciones urbanas, Antioquia, Universidad de Antioquia.

- (1998), "Las estrategias de memoria y olvido en la construcción de la identidad urbana: el caso de Barcelona”, en D. Herrera Gómez (coord.), Ciudad y cultura. Memoria, identidad y comunicación, Antioquia, Universidad de Antioquia, pp. 95-125.

Donzelot, Jacques (2004), "La ville á trois vitesses: relégation, périurbanisation, gentrification urbaine”, Esprit, núm. 263, pp. 14-39.

— (1999), "La nouvelle question urbaine”, Esprit, núm. 258, pp. 87-110.

Giglia, Ángela (2001), "Introducción”, Perfiles Latinoamericanos, año 9, núm. 19, pp. 7-11.

Girola, María Florencia (2005a), "Procesos de recualificación urbana desde una perspectiva comparativa: análisis de casos en la centralidad y la periferia del Área Metropolitana de Buenos Aires", III Jornadas de Investigación en Antropología Social, Buenos Aires, Universidad de Buenos Aires, 3 a 5 de agosto.

— (2005b), "Nuevos paisajes residenciales en el Gran Buenos Aires: los emprendimientos cerrados entre el urbanismo escenográfico y el urbanismo afinitario", Litorales, revista electrónica, Universidad de Buenos Aires, FFyL, Instituto de Geografía. Dirección electrónica: www.litorales.filo.uba.ar.

— y Mónica Lacarrieu (2004), "Lugares soñados, lugares temidos: experiencias urbanas en tiempos de crisis”, VII Congreso Argentino de Antropología Social, Córdoba, CAAS, 25 a 38 de mayo.

—_ Mónica Lacarrieu y Guenola Capron (2005), "Procesos de periurbanización en el Área Metropolitana de Buenos Aires: estrategias de seguridad y construcción social del miedo en conjuntos residenciales cerrados", I Congreso Latinoamericano de Antropología, Rosario, ALA, 11 a 15 de julio.

Grassi, Estela (2003), Políticas y problemas sociales en la sociedad neoliberal. La otra década infame (I), Buenos Aires, Espacio.

Jaillet, Marie Christine (2004), "L'espace periurbain: un univers pour les classes moyennes”, Esprit, núm. 263, pp. 40-64.

(1999), “¿Peut-on parler de sècession urbaine à propos des villes européenne?”, Esprit, núm. 258, pp. 133-152.

Janoschka, Michael (2005), "El modelo de ciudad latinoamericana. Privatización y fragmentación del espacio urbano de Buenos Aires: el caso Nordelta", en Max Welch Guerra (ed.), Buenos Aires a la deriva. Transformaciones urbanas recientes, Buenos Aires, Biblos, pp. 96-131. 
Lacarrieu, Mónica (2005), "Nuevas políticas de lugares: recorridos y fronteras entre la utopía y la crisis", en Max Welch Guerra (ed.), Buenos Aires a la deriva. Transformaciones urbanas recientes, Buenos Aires, Biblos, pp. 363-395.

(1999), "Informe final. Beca Esther Hermitte para Investigación en Antropología Social”, Buenos Aires, Fundación Antorchas.

Patriota de Moura, Cristina (2003), "Vivendo entre muros: o sonho da aldeia", en Gilberto Velho y Karina Kuschnir (comps.), Pesquisas urbanas. Desafios do trabalho antropológico, Río de Janeiro, Jarga Zahar, pp. 43-54.

Pires do Rio Caldeira, Teresa (1996), "Enclaves fortificados: a nova segregaçao urbana”, Novos Estudos, núm. 47, pp. 155-176.

Prévot Schapira, Marie-France (2001), "Fragmentación espacial y social: conceptos y realidades”, Perfiles Latinoamericanos, año 9, núm. 19, pp. 33-56.

(2000), "Segregación, fragmentación, secesión. Hacia una nueva geografía social en la aglomeración de Buenos Aires", Economía, Sociedad y Territorio, vol. 2, núm. 7, pp 405-431.

— (1999), “Amérique latine: la ville fragmentée”, Esprit, núm. 258, pp. 118-132.

Ríos, Diego (2005a), "Planificación privada y desastres de inundación. Las urbanizaciones cerradas polderizadas en el municipio de Tigre, provincia de Buenos Aires, Argentina", Economía, Sociedad y Territorio, vol. 5, núm. 17, pp 63-83.

- (2005b), "Producción privada del espacio urbano residencia y estado. El caso de la megaurbanización cerrada Nodelta en el municipio de Tigre”, III Jornadas de Investigación en Antropología Social, Buenos Aires, Universidad de Buenos Aires, 3 a 5 de agosto.

Safa Barraza, Patricia (1999), "Construir mundos, levantar muros y preservar patrimonios: ¿una alternativa de vida en las grandes ciudades? Condominios y fraccionamientos cerrados en la Ciudad de México" (mimeo.).

Sassen, Saskia (1999), La ciudad global: Nueva York, Londres, Tokio, Buenos Aires, Eudeba.

Svampa, Maristella (2005), La sociedad excluyente. La Argentina bajo el signo del neoliberalismo, Buenos Aires, Taurus.

- (2001), Los que ganaron. La vida en los countries y barrios privados, Buenos Aires, Biblos.

Teixeira de Andrade, Luciana (2004), "Auto-segregaçao e vida urbana nos condominios residencias fechados”, XXIV Reunión Brasileña de Antropología, Olinda.

Welch Guerra, Max y Paula Valentini (2005), "Torres jardín en Buenos Aires: proyecciones de una tipología habitacional”, en Max Welch Guerra (ed.), Buenos Aires a la deriva. Transformaciones urbanas recientes, Buenos Aires, Biblos, pp. 74-95.

Zukin, Sharon (1996), "Paisagens urbanas pós-modernas: mapeando cultura y poder”, Revista do Patrimonio Histórico e Artístico Nacional, pp. 205-219. 